\title{
GOD, EVIL, AND EVOLUTION
}

\author{
BRIAN ZAMULINSKI
}

Kainan University

\begin{abstract}
Most evil is compatible with the existence of God if He has an aim that $\mathrm{He}$ can achieve only by using an unguided process of evolution and if $\mathrm{He}$ cannot be condemned for trying to achieve His aim. It is argued that there is an aim that could reasonably be attributed to God and that God cannot achieve it without using evolution. There are independent grounds for thinking an evolutionary response is necessary if God is to be defended at all. Issues that require further investigation are pointed out and desirable features of the evolutionary response indicated.
\end{abstract}

\section{INTRODUCTION}

If God is a moral agent and if it is therefore appropriate to judge Him in light of moral standards of right and wrong, and good and bad, then any adequate response to the evidential problem of evil must involve the theory of evolution by variation and natural selection. Evolution enables us to show that, in most cases, neither natural nor moral evil gives us reason to doubt the existence of God qua moral agent, provided that He could have a purpose that requires Him to use a process of evolution that He does not control and in which He does not intervene, and provided that the value of achieving the goal outweighs the disvalue of the suffering and death that evolution by variation and natural selection inevitably involves. The only possible evils that cannot be explained in this way are those in cases in which God does not intervene miraculously to prevent them after $\mathrm{He}$ has achieved His aim - and the existence and number of such cases depends on His aim. Moreover, evolution is necessary to explain some evils in a way that exonerates God qua moral agent, which means that if there is no evolutionary response, there can be no complete response. 
In arguing for the foregoing claims, the first step is to distinguish this project from the free-will and the soul-making responses. The second is to suggest an aim such that God would need to use an unguided evolutionary process in order to achieve it. The aim suggested will be the development of persons who are capable of freely desiring, and of freely committing themselves to, a relationship with God. The third is to show that the occurrence of an unguided evolutionary process explains most natural and moral evil. The fourth is to argue that it is impossible to exonerate God qua moral agent without relying on evolution. Since the purpose of this paper is just to show that evolution must play a role in any adequate response to the evidential problem of evil and not to provide an actual defence or theodicy, there will be no attempt to go further. Once the argument is complete, I will briefly discuss the possibility that evolutionary ethics puts a question mark against the greater good approach, the consequent implications for our understanding of the nature of God, and a couple of ways of dealing with any residual evils. I will follow with some brief evaluative remarks.

\section{A NEW APPROACH}

One philosopher neatly summarizes the two prevailing approaches as follows: "According to the 'free-will defence', evil and suffering are necessary consequences of free-will. Proponents of the 'soul-making argument' ... argue that a universe which is imperfect will nurture a whole range of virtues in a way impossible either in a perfect world, or in a totally evil one." Soul-making also involves freedom. "[It] is the process by which .... agents freely and autonomously come to develop and perfect certain valuable traits of moral character and to know and to love God."

The position here is distinguishable from the free will response in that evil is not primarily the consequence of the possession of free will by individuals but a concomitant of the only process that can bring into existence organisms that are capable of freely committing themselves to God, and freely desiring to do so. The argument is not that "if God grants

\footnotetext{
${ }^{1}$ Peter Harrison, “Theodicy and Animal Pain," Philosophy 64 (1989), pp. 79-92: 79.

${ }^{2}$ G. Stanley Kane, "The Failure of Soul-Making Theodicy," International Journal for Philosophy of Religion 6 (1975), pp. 1-22: 1.
} 
us significant freedom, he cannot control how it will be used." ${ }^{3}$ On the view here, if there are objective and independent moral standards, there will be evil in some possible worlds in which no free agents ever develop. Moreover, for all that is said here, free agents need not be responsible for any evil, although they certainly can be responsible for some. The position here is also distinguishable from the soul-making argument in that it need not be the case that the function of freedom is to enable a process of soul-making, or that the desirability of soul-making justifies the existence of most evils. It is possible to hold that God wants there to be beings capable of acting freely without intending that there be any soul-making at all. In sum, the position here neither presupposes nor entails either the free-will or the soul-making theodicy; it is independent of them.

Naturally, the aim attributed to God in this paper is speculative: there is no way to demonstrate that it is His aim. However, it is also speculative that God particularly wants to create beings with free will and speculative that God's aim is soul-building. Indeed, any response to the evidential argument from evil must be speculative. Strictly speaking, the most that can be shown is that the evil that we observe does not count against the existence of God because He could have a good reason to permit it.

When it comes to good reasons for permitting evil, the evolutionary response is far more powerful than some of its extant competitors. For instance, Swinburne's contention that natural evils are somehow educational is implausible. ${ }^{4}$ Swinburne talks of other animals "learning" from the fate of a fawn: "It is good for the fawn caught in the thicket in the forest fire that his suffering provides knowledge for the deer and other animals who see it to avoid the fire and deter their other offspring from being caught in it." ${ }^{\prime 5}$ The trouble is that some deer starve to death in places like Canada every winter but other creatures appear to have learned nothing about avoiding hunger as a result. In contrast, as we will see shortly, the evolutionary response has no difficulty with such cases. If

\footnotetext{
${ }^{3}$ David Basinger and Randall Basinger, “The Problem with the Problem of Evil," Religious Studies 30 (1994), pp. 89-97: 91.

${ }^{4}$ See the works of Richard Swinburne, starting with his "Natural Evil," American Philosophical Quarterly, 15 (1978), pp. 295-301.

${ }^{5}$ Richard Swinburne, Providence and the Problem of Evil, Oxford: Clarendon Press, 1998, p. 103.
} 
God has an aim that can only be achieved through an unguided process of evolution and if He cannot be condemned for trying to achieve it, then starving deer will not undermine the response at all. Neither will any of the other cases of injury, disease, death, and extinction that we know to have occurred in the course of evolution. Since it cannot be argued that evolution could take place in a world that is radically different from the actual one in relevant respects and since evolution occurs as a result of differences in viability and fertility, it appears to be literally impossible for the advocate of the evidential argument from evil to discover counter-examples that can be used to undermine the evolutionary response. The power of the evolutionary response is a good reason to explore it.

\section{WHY THE ABILITY TO ACT FREELY MUST BE A PRODUCT OF EVOLUTION}

As for God's purpose, let us suppose that God wants there to be persons who are capable of freely desiring to enter into a relationship with Him and of freely committing themselves to the relationship. I shall refer to such persons as "relationship-capable persons." When it comes to how relationship-capable persons could possibly come into existence, there are four cases to consider. First, there is the case where God manufactures them, where manufacturing them means either creating them fully formed by fiat, or by establishing initial conditions and deterministic laws of nature in a world that will inevitably bring them into existence. Second, there is the case where God establishes the initial conditions and laws of nature in an indeterministic universe and then uses artificial selection to develop relationship-capable persons. Third, there is the case where evolution does not occur and individuals sometimes chance to desire to enter into a relationship with God. And, finally, there is the case where God establishes the initial conditions and laws of nature in an indeterministic universe and leaves it alone in the hope that relationshipcapable persons will eventually evolve. Relationship-capable individuals can come into existence only in the last set of circumstances. The possibility that God might nurture individuals as a parent nurtures children is not an additional option because the capacity for free action is not an acquired characteristic. 
As for the first possibility, God cannot manufacture relationshipcapable persons. The argument against the possibility of manufacturing them involves considering the possibilities with respect to people and their relationship with God: people will either desire to some positive degree to enter into a relationship with Him, or be indifferent as to whether they do so, or be positively disinclined to do so. Now, on the one hand, if God manufactured relation-capable persons who had characteristics that inclined them to enter into a relationship with Him, then God would have contributed to bringing it about that they desired to enter into the relationship and to the extent that God had contributed to bringing it about that they desired to enter into the relationship, they would not freely desire to do so.

Consider an analogy. If someone trains a watchdog to attack trespassers, he is responsible for its actions if it attacks someone. He would also be responsible if he genetically modified the watchdog so that training it was unnecessary. And, he would be even more responsible if he stipulated the entire genome of the attack animal. To the extent that the trainer is responsible for the watchdog's attacking someone, the watchdog does not attack freely. Similarly, if God specified the genetic make-up of an individual, God would be responsible for the individual's actions. He would be all the more responsible if He determined all the situations the individual would confront. In general, if another agent is responsible for what a person does, then the latter does not act freely - if a puppeteer controls the outcome, the puppet's movements are not free. Hence, manufactured individuals who wanted to enter into a relationship with God would not do so freely. This would be true even in a world in which compatibilism was true: compatibilism does not relieve people who train watchdogs of their responsibility and it would not relieve God of responsibility either.

On the other hand, if God manufactured people with characteristics that made them indifferent or disinclined, then He would be creating persons who did not desire to enter into a relationship with Him. It follows that, whatever God did in the way of manufacturing individuals, He could not create precisely the kind of persons that, by hypothesis, $\mathrm{He}$ wants to create. To return to the original formulation of the claim, God cannot manufacture persons who freely desire to enter into, and to commit themselves to, a relationship with Him. John Hick holds that God 
could have created free individuals by fiat but in fact used evolution. ${ }^{6}$ Ignoring the fact that Hick's stance entails that God is a sadistic monster, because He would have no good reason to choose more suffering over less and an evolutionary process would involve more suffering than fiat creation, fiat creation is a form of manufacturing and the argument here is that free individuals cannot be manufactured at all.

Now, consider the case in which God uses artificial selection. In this case, God does not create fully-formed relationship-capable persons. He is therefore not responsible for all of their characteristics. However, when there is evolutionary competition between individuals who are more likely to have relationship-capable descendants and individuals who are less likely to have them, God intervenes in such a way that the former win the competition. He might do this by, say, by intervening to prevent the latter from producing as many offspring as the former even if objective environmental conditions were such that they were not at a disadvantage with respect to fertility. The trouble is that someone who bred watchdogs to do a particular kind of action when certain conditions obtained would be responsible for their actions of that kind in those kinds of circumstances. Similarly, God would still be responsible for the fact that people are relationship-capable. As contended above, if another agent is responsible for an agent's actions, then the latter does not act freely. In this case, God would be responsible for people desiring to enter into a relationship with Him and for their committing themselves to the relationship when they did enter one. Hence, they would do neither of these things freely. Consequently, God could not "breed" relationship-capable persons. Artificial selection offers no advantages over manufacturing when it comes to producing relationship-capable persons as defined.

Third, although God could create an indeterministic world complete with inhabitants that occasionally chanced to want to enter into a relationship with Him, such individuals would be incapable of truly committing themselves to the relationship: what chance could bring into existence, chance could eliminate, and commitment cannot be a matter of chance. It is also questionable whether we could accurately describe individuals who just chanced to desire to enter into a relationship with God as persons who freely desired to enter into the relationship: random

${ }^{6}$ John Hick, Evil and the God of Love, London and New York: Macmillan, 2007. 
events are not free actions and, similarly, desiring something by chance is not the same as desiring it freely.

Therefore, God's only option is to create an indeterministic universe in which it is possible for relationship-capable persons to evolve and to leave it alone in the hope that they will evolve. If God wants there to be relationship-capable persons as defined, then God must "use" evolution. This situation differs from the pure chance situation because, while it is true that it would be a matter of chance whether relationship-capable persons evolved, it would not be a matter of chance, once they did exist, whether they desired to enter into a relationship with God, whether they committed themselves to God, or whether they remained committed to Him. This type of claim is frequently true in biology, which increases its credibility in the present case. For instance, while it is a matter of chance that mammals predominate on our planet, it is not a matter of chance that mammals nurse their young when they have them. Animals that nurse their young evolved through a series of accidents but there was selection for the retention of the mutations that resulted in nursing because individuals with them were biologically fitter than their competitors. Moreover, God would not be responsible for anyone's desires or commitments in a way that would preclude his freedom. In sum, God has no option but to "use" an unguided evolutionary process to "create" relationship-capable persons. Since it is possible that God wants to create relationship-capable persons, it is possible that God has a goal that can be achieved only by creating a world in which life originates in an indeterministic world and evolves, naturally and without interference.

\section{HOW EVOLUTION DISPOSES OF EVILS}

Let us continue to assume that God wants to create relationship-capable persons. $^{7}$ As just argued, He can achieve this only by creating an indeterministic universe in which life can arise and evolve into an array of complex forms and in which He does not intervene, allowing the evolu-

\footnotetext{
${ }^{7}$ Fransisco Ayala also claims that evolution by variation and natural selection enables us to avoid condemning God but his argument is incomplete. Ayala does not discuss any possible goals for God or any sense in which He could be said to be good. See his Darwin's Gift: To Science and Religion, Washington DC: Joseph Henry Press, 2007.
} 
tionary process to unfold without any guidance. The world will have to be a dynamic one: there will have to be changes that can drive evolution by altering the conditions in which organisms try to survive and reproduce. Of course, on the one hand, the world cannot be too dynamic: the changes must not occur so quickly that species become extinct too soon. On the other, it cannot lack dynamism: a world in which there was an ecological equilibrium and few mutations would be one in which little or no natural selection would occur. In short, the world will have to be one in which there are accidents, diseases, predators, natural disasters, and extinctions, albeit not an overwhelming number of them. In turn, this means that it will have to be a world in which there are many natural evils. It follows that natural evils do not constitute evidence against the existence of God unless He could achieve His aim without using evolution or there are reasons to condemn Him for trying to achieve it in the first place.

It might be thought that it is a reasonable objection that God could have achieved His aim in a world that is less or more dynamic than the actual world. In fact, such an objection would be pointless because there is an inverse relationship between how dynamic the world is and how long the process will probably take. If a less dynamic process takes longer than a more dynamic one, a less dynamic process means less suffering per generation but more generations of suffering while a more dynamic process means more suffering per generation but fewer generations of suffering. Provided that the process is not so fast that it burns itself out or so slow that it never gets very far, there will be little if anything to recommend a more dynamic state over a less dynamic one, or vice-versa.

Moral evil is no evidence against the existence of God either. If moral agents are products of evolution by variation and natural selection and if God must refrain from intervening in the process in order to achieve His aim, moral evils can arise whatever God might prefer. Indeed, moral evils are liable to arise, because it is highly probable that any moral agents that evolve will be morally imperfect. One reason that they will probably be morally imperfect is that imperfection is inevitable in the products of variation and natural selection and there is liable to be some moral imperfection as well. Another is that the biological interests of organisms can conflict with moral requirements. Yet another is that there will be variations in moral character just as there are with respect to other 
features of organisms and there will always be some people at the extreme ends of the continuum just by chance - there will be great potential sinners as well as potential saints. Whereas natural evils are a necessary means to the end, since they are needed to drive the evolutionary process, morally imperfect beings that do wrong would be an inevitable by-product of the process. It follows nevertheless that the existence of moral evil is no reason to condemn God either, again unless there is reason to condemn his goal.

As the preceding paragraphs make clear, an evolutionary approach would provide a comprehensive explanation of evil, explaining both natural and moral evils very readily, which is a great advantage. In fact, the ease and comprehensiveness naturally moves one to wonder whether it can really be that easy. The answer is affirmative. Unless there are cases in which God does wrong by omission after He has achieved His aim, there appears to be nothing that we consider an evil that is neither caused by the dynamic nature of the world we inhabit, nor brought about by amoral organisms that have evolved in the world, nor brought about by morally imperfect moral agents - moral agents who are imperfect because they are also products of the evolutionary causal processes that are driven by the dynamic nature of the world. The first category includes floods, earthquakes and hurricanes; the second includes bacteria, viruses, parasites, and predators; and the third includes crime, indifference, and ideological insanity of the kind that dominated the $20^{\text {th }}$ century. There are no other kinds of evil in addition to these three.

Another advantage of an evolutionary approach is that it makes it unnecessary to come up with explanations for most particular instances of evil - such as the starving deer of Canada mentioned earlier. Evil is an inevitable or highly probable concomitant of an unavoidable process if God needs to use an evolutionary process in which He does not intervene in order to achieve his aim. From an evaluative standpoint, it is enough to know that the process will bring about a variety of evils; explanations for particular instances of evil will often be causal, not moral. We do not have to justify the death by starvation of individual deer in terms of the putative benefits of their deaths. If there is no reason to condemn God for using evolution to achieve His goal, there is no reason to condemn Him for the consequences of the process. 


\section{WHY EVOLUTION IS NECESSARY TO DISPOSE OF EVIL}

The fundamental argument to the effect that an evolutionary defence is necessary to avoid a moral condemnation of God qua moral agent is as follows. The independent scientific evidence is such that there can be no reasonable doubt that an evolutionary process has occurred on our planet. ${ }^{8}$ It is also such that there can be no doubt that the evolutionary process involves pain, suffering, and death, and is the cause of a great deal of what we consider evil. There would be a very great deal of pain and suffering even if we took into consideration only the pain and suffering of actual and potential human moral agents, i.e., relationship-capable persons. It follows that if we are to avoid condemning God, then the evolutionary process is necessary for some reason. When it comes to avoiding a condemnation of God in the face of the evils that we observe, any realistic option must include an evolutionary response.

Anyone who wanted to deny that an evolutionary response is a necessary part of any realistic option would have to hold that evolution is merely a façade behind which God is working out His purposes. One problem with this is that it adds unnecessary complexity. Another is that too many events are too distant, temporally or spatially or both, for us to be able to show that they have all served some specific purpose. Indeed, there are too many contemporary events for us to demonstrate that they all serve a purpose. Since there is not even the beginning of an explanation in many cases, the contention that the matter is beyond our understanding is really an appeal to ignorance: it amounts to declaring that the critic cannot prove that there is no good, non-evolutionary, reason for the evils that we observe and that, therefore, there is, or could be, a reason. Naturally, it would be possible to invoke free-willed demons in response to natural evil. ${ }^{9}$ One problem with doing so is that it would also be necessary to explain why God allows their continued existence. More importantly, there is no independent evidence for their existence or activities. In contrast, as already mentioned, there is plenty of independent evidence that evolution has occurred and that the world is of such a nature that evolution can take place. The germ theory of disease

${ }^{8}$ See Kenneth R. Miller, Finding Darwin's God, New York: Harper Collins, 1999, for a survey of the evidence for evolution and against a variety of creationist alternatives.

${ }^{9}$ See Alvin Plantinga, God, Freedom and Evil, London: Allen \& Unwin, 1974. 
has ousted the demon theory and the evolutionary theory of natural evil ought to oust the demon theory as well.

There are some theists who deny that evolution occurs. No doubt, they will want to reject the contention that an evolutionary response to the evidential problem of evil must be part of any realistic response. In order to try to prevent them from doing so, I shall present an example that shows that it is not necessary to make an explicit appeal to the occurrence of evolution in order to show that only an evolutionary response will do. The example is one in which the evidence for a state of affairs is non-evolutionary but in which the only way to ensure that God can avoid condemnation is to account for it in evolutionary terms. The example could be multiplied many times over.

The example involves an argument from imperfection, which requires a bit of explanation. The existence of imperfections is compatible with there being an evolutionary explanation for a feature and with its being the case that the feature is highly advantageous in most circumstances. In an evolutionary world, everything is jerry-built and jury-rigged, and peculiarities and drawbacks are inevitable. An argument from imperfection is to the effect that if the feature were created by an omnipotent, omniscient, and omnibenevolent Being other than through the use of evolution, then the feature would exist, it would be advantageous, but it would be without the attendant drawbacks unless they were inseparable from the feature for some reason. An example that can be used to illustrate the argument is the human eye. It always has two flaws: the nerves that bundle together to form the optic nerve attach to the front of the retina and the optic nerve goes through the middle of the retina. ${ }^{10}$ The attachment of the nerves to the front blurs our vision and the hole in the middle of the retina creates a blind spot. There is no necessity to the arrangement, which we know because the eye of the squid has nerves that attach to the back of the retina. Therefore, the human eye has eliminable defects, a designer with the attributes of God would do better, and hence the human eye is not a product of divine design.

Turning to the example itself now, there are evils caused by the existence of cognitive biases that render human beings less than optimally rational in some circumstances. For instance, one cognitive bias is con-

${ }^{10}$ See George C. Williams, The Pony Fish's Glow, New York: Basic Books, 1997. 
firmation bias, which is the tendency to look for confirming evidence and to fail to look for potentially disconfirming evidence that is equally or more important. ${ }^{11}$ This does not have to do with a moral flaw in human beings but with a cognitive one: it is not a matter of people believing what they want to believe for some reason because it occurs in cases in which people have no stake in the outcome of the inquiry. It can lead to things like unjust racial stereotypes, because people notice behavior on the part of members of racial groups when the behavior conforms to the stereotype, fail to notice behavior that does not conform to it, and incorrectly conclude that the stereotype is true. Another widespread cognitive defect is that many human beings are more suggestible than is either necessary or desirable. It is possible to implant false memories of being lost in a mall in a quarter of the subjects. ${ }^{12}$ Leading questions alone can result in false memories. ${ }^{13}$

Whatever the explanation for the origin of these tendencies, they are not always conducive to morally positive outcomes. This is obvious in the case of racial bigotry. However, it is also easy to imagine how a combination of confirmation bias on the part of investigators and suggestibility on the part of children being questioned could, say, result in false allegations of child abuse. This is undesirable not merely because innocent people can be falsely accused but also because, in the long run, false accusations in some cases will undermine the credibility of children generally, which will make it more likely that real child abusers will be able to get away with their crimes.

If human beings have to be products of evolution by variation and natural selection in order for God to achieve His purpose in bringing them into existence, the evil that results from cognitive biases does not support the contention that there is eliminable evil in the world and, therefore, that there is no God. In contrast, there are grave difficulties

\footnotetext{
${ }^{11}$ See Raymond S. Nickerson, "Confirmation Bias: A Ubiquitous Phenomenon in Many Guises," Review of General Psychology 2 (1998), 175-220.

${ }^{12}$ See Elizabeth Loftus and Jacqueline Pickrell, "The Formation of False Memories," Psychiatric Annals 25 (1995), 720-725. For a general discussion of human memory as well as this phenomenon, see Daniel Schachter, The Seven Sins of Memory, Boston: Houghton Mifflin, 2001.

${ }^{13}$ Loftus points out that leading questions can result in false memories. See Elizabeth Loftus, "Make-Believe Memories," American Psychologist 58 (2003), 867-873.
} 
if God is responsible for the characteristics that His creations possess. For instance, the free will defence fails. False allegations of child abuse produced by confirmation bias and suggestibility do not occur because people have free will and have used their free will to do wrong. Instead, they occur because people are flawed inquirers. Indeed, with confirmation bias and human suggestibility, even the most selfless and well-intentioned investigators would sometimes fall into error unless they were aware of their biases and took steps to obviate their influence. Moreover, the tendencies were only discovered in the $20^{\text {th }}$ century, so no one could have been aware of them until recently. As for soul-building, the biases prevent people from acting in a morally responsible way even if they want to, so it is hard to see that they do anything but prevent soul-building.

Even if confirmation bias and suggestibility were useful in normal circumstances, the evidence for imperfection is that they lead us astray in some cases; and that there are now people who know of them, who still function adequately, and who are less susceptible to the kind of moral mistakes to which people ignorant of them are susceptible. Since people who learn about suggestibility and confirmation bias can eliminate, or compensate for, their influence without any adverse consequences, neither is necessary for a greater good. A creator who had the usual attributes imputed to God and who created us without using evolution could have made us better than we actually are. The only possible excuse for Him is that He needs to use unguided evolution to achieve His aim. Since God could have made us so that we were neither suggestible nor susceptible to confirmation bias (when inappropriate), the occurrence of any evil that can be attributed to those flaws means that there is eliminable evil in the world - unless God must use an evolutionary process in which He cannot interfere.

The example does not presuppose the truth of evolution. We do not need to appeal to evolution to learn that cognitive biases exist or to discover that they can cause us to act in ways that are not ethically optimal. In sum, we do not need evolution to set up the example but we do need it to respond to it adequately. 


\section{OPEN ISSUES}

The evolutionary response has been presented as a greater good response. There is a background assumption that God is justified in creating a world in which life can evolve despite the suffering involved because relationship-capable persons are worth it. In fact, however, evolution may actually put the greater good approach in doubt. It will put it in doubt if evolution has not merely produced true beliefs about a pre-existing moral reality but has created morality itself. This seems to be a real possibility. I have myself put forth an argument that evolution by variation and natural selection can produce objective moral facts to which we have intuitive access. ${ }^{14}$ The reason evolution might thus put the greater good response into doubt is that a morality that is a product of evolution cannot justify the very process that brought it into existence. In light of the possibility that evolution has created morality itself, it cannot just be assumed that value "transcends" the physical world and its inhabitants. Hence, any response that takes a greater good approach, that assumes that God is a moral agent, but that fails to include a demonstration that morality is independent of the biological realm, will be fundamentally incomplete. ${ }^{15}$

Furthermore, if morality itself is a product of evolution, the prevailing concept of God will have to be modified. If morality is a product of evolution, moral agents will be products of evolution as well. If morality and moral agents are products of evolution, not only will there be no greater good in light of which we can evaluate God and judge Him as though He were a moral agent, but also God will be outside the range of the kind of moral evaluation that is properly applied to moral agents. In that case, the goodness of God could not be glossed as moral perfection - He could not be viewed as a moral agent who never does wrong and who never does a bad thing. Instead, He would have to be accounted wholly good merely from the perspective of relationship-capable per-

\footnotetext{
${ }^{14}$ See Brian Zamulinski, Evolutionary Intuitionism: A Theory of the Origin and Nature of Moral Facts, Montreal and Kingston: McGill-Queen's University Press, 2007.

${ }^{15}$ For examples - in addition to Hick and Swinburne - of this kind of defective approach, see: Keith Ward, Rational Theology and the Creativity of God, Oxford: Blackwell Publishing, 1982, and Robin Attfield, Creation, Evolution and Meaning, Burlington, VT, and Aldershot: Ashgate Publishing, 2006.
} 
sons - in the way natural phenomena are sometimes judged to be good. Naturally, a God whose goodness did not amount to moral perfection could still be a loving God.

Finally, if relationship-capable persons have come into existence, it is necessary to explain why the evolutionary process continues and why God does not prevent evil from afflicting relationship-capable persons. There is more than one way to proceed. One way is to supplement the evolutionary response with one of the more traditional responses. Perhaps, for instance, God wants both relationship-capable persons to exist and for them to undergo a process of soul-building. Another way is to attribute a more complex aim to God. Perhaps, He does not just want to create relationship-capable persons full stop but to create relationshipcapable persons who are willing to work to develop just and caring societies. In that case, He would not ordinarily rescue people when they needed saving but would leave the rescue to their fellow human beings. Also, in that case, it would be harder to discover evils that could constitute evidence against God. Indeed, it might actually be possible to conceive of an aim that made it impossible to discover such evils.

It has been assumed in this paper that God's aim is the creation of relationship-capable persons because the assumption made it possible to argue - without distractions - that God had to use evolution. It is now possible to suggest a more complicated hypothesis without the same possibility of confusion, although doing more than making the brief suggestion in the previous paragraph is beyond the scope of this paper. Whatever the aim we attribute to God, the evolutionary response greatly reduces the number of the evils that can potentially be used as evidence against the existence of God, if it does not eliminate them completely.

\section{SOME EVALUATIVE REMARKS}

No matter the answers to the questions raised in the previous section, the necessity and desirability of the evolutionary response means that the only way forward is through attempts to answer them. Moreover, while an evolutionary response is necessary if God is to be defended at all, there are reasons to think that an evolutionary response ought to be 
attractive to theists even if it were not necessary. First, as Derk Pereboom points out, the problem of evil "still constitutes the greatest challenge to rational theistic belief." ${ }^{\prime 6}$ Without the evolutionary response, all that can be done with regard to natural evil is to "hold that God's purposes for permitting evil are inscrutable; or ... reject the assumption that gratuitous evil is incompatible with theism; or, finally, rely on evidence ... in support of the existence of God in order to offset the negative evidential impact of the problem of natural evil." ${ }^{17}$ None of the three options mentioned is both promising and satisfactory. Hence, evolution provides the foundation for a reasonable response in a situation in which other options are realistically unavailable.

Second, by going beyond mere compatibility with evolution, the embrace transmutes evidence for evolution from evidence that has been thought to cause difficulties for theism into evidence that can be used to support theism indirectly by undermining the argument from evil. The argument does not deny God's creation of the world but holds that God had to create a certain sort of world if He was to achieve His aim. All it undercuts is a $19^{\text {th }}$ century variant of the argument to design that becomes implausible - even in the absence of evolutionary theory - once we start taking observable imperfections seriously. Of course, the notion that evolution is God's method of creation is not new. ${ }^{18}$ What is new is the suggestion of a reason why God would use a process of evolution in which He does not intervene. There is certainly a great deal to be said for an approach that enables theism to avoid conflict with contemporary science.

Finally, if God needs to use evolution in order to achieve His aim and if the evolution of human beings means that He has actually achieved His aim, humanity could once again be viewed as the crown of creation. It has been said that humanity has suffered a crisis of confidence because science has eliminated the justification for thinking that we are special: Copernicus dislodged us from the physical centre of the universe

${ }^{16}$ Derk Pereboom, “The Problem of Evil,” Ch. 7 in William E. Mann, ed., The Blackwell Guide to the Philosophy of Religion, Oxford: Blackwell Publishing, 2005, 148-170: 167.

${ }^{17}$ Nick Trakakis, "Is theism capable of accounting for any natural evil at all?" International Journal for the Philosophy of Religion 57 (2005), 35-66: 59.

${ }^{18}$ Miller advances this contention in Finding Darwin's God. 
and Darwin showed that we are just another animal. ${ }^{19}$ However, if God's aim involves humanity in particular, that is, if we are the kind of being He wanted to bring into existence through the evolutionary process, it would be the case that the universe was created in order to bring beings like us into existence and there would be good reason for God to be especially concerned with us. Neither the obscure location of our planet nor the fact that we are products of evolution by variation and natural selection would give us any reason for doubt on these counts.

\section{CONCLUSION}

The prevailing reactions on the part of theists to the idea of evolution by variation and natural selection range from extreme hostility to acceptance that theism and evolution are compatible. Those who go further to say that evolution is God's method of creation do not usually explain why He would use it. The view here is that evolution must be God's method of creation; that it is possible that the reason He must use it is that He wants to create relationship-capable persons and evolution is the only way in which He can do so; that if He has to use evolution, then the argument from evil can be largely or completely neutralized; and that the argument from evil cannot be neutralized completely without appealing to evolution. If so, the prevailing reactions are not the most appropriate from a theist's point of view. Since theism needs evolution, the appropriate reaction is an enthusiastic embrace.

${ }^{19}$ See Ayala for a relevant discussion. 